PAPER 36

\title{
OPTICAL OBSERVATIONS OF SOLAR DISTURBANCES CAUSING TYPE II RADIO BURSTS
}

\author{
R. G. GIOVANELLI \\ Division of Physics, National Standards Laboratory, Sydney, Australia \\ J. A. ROBERTS \\ Radiophysics Laboratory, Commonwealth Scientific and Industrial \\ Research Organization, Sydney, Australia
}

During 1956-57, 15 type II radio bursts have been recorded on the Dapto radio spectrograph during times of observation with the Sydney $\mathrm{H} \alpha$ flare patrol camera. We believe that we have established identifications of the optical disturbances responsible for 13 of these bursts, and alternative identifications for the remaining two. As Table I shows, some of these were

TABLE I

SUMMARY OF TYPE II BURSTS AND IDENTIFICATIONS

\begin{tabular}{|c|c|c|c|c|c|c|c|}
\hline \multicolumn{3}{|c|}{ Date } & $\begin{array}{l}\text { Harmonics } \\
\text { Observed }^{1}\end{array}$ & Optical Event & $\begin{array}{c}\text { Radial } \\
\text { Distance }\end{array}$ & $\begin{array}{l}\text { Velocity } \\
(\mathrm{km} / \mathrm{sec})\end{array}$ & $\begin{array}{l}\text { Apparent } \\
\text { Flare Area }^{3}\end{array}$ \\
\hline \multirow[t]{7}{*}{1957} & Mar & 1 & - & Ejected prominence & $1.00+$ & 350,280 & - \\
\hline & Mar & & - & Ejected prominence & $1.00+$ & 490 & - \\
\hline & Sep & 24 & - & Flare-surge & 1.00 & $\geq 200$ & 10 \\
\hline & Sep & 24 & - & Surge & 1.00 & 670 & - \\
\hline & Jan & 31 & 1,2 & $\begin{array}{l}\text { Disappearing filament fol- } \\
\text { lowed by two parallel flares }\end{array}$ & 0.50 & - & 1050 \\
\hline & Nov & 29 & - & $\begin{array}{l}\text { Disappearing filament fol- } \\
\text { lowed by two parallel flares }\end{array}$ & 0.95 & - & 600 \\
\hline & Aug & 6 & 1,2 & Diffusely expanding flare & 0.43 & - & 70 \\
\hline \multirow[t]{2}{*}{1956} & Jan & 19 & 1,2 & Flare & 0.56 & 一 & 450 \\
\hline & Nov & 13 & $\begin{array}{l}\text { inadequate } \\
\text { record }\end{array}$ & Flare & 0.77 & - & 385 \\
\hline \multirow[t]{6}{*}{1957} & Nov & 13 & 1,2 & Flare & 0.59 & - & 170 \\
\hline & Nov & 22 & 1,2 & Flare & 0.61 & - & 385 \\
\hline & Dec & 6 & 1,2 & Flare & 0.75 & - & 350 \\
\hline & Dec & 20 & 1,2 & Flare & 0.34 & - & 175 \\
\hline & Jul & 17 & 1,2 & $\begin{array}{l}\text { Flare or } \\
\text { disappearing filament }\end{array}$ & $\begin{array}{l}0.48 \\
0.80\end{array}$ & - & 220 \\
\hline & Nov & 6 & - & $\begin{array}{l}\text { Ejected prominence or } \\
\text { Flare-surge }\end{array}$ & $\begin{array}{l}1.00++ \\
0.90\end{array}$ & 240 & $\overline{30}$ \\
\hline
\end{tabular}

1 Absence of a comment indicates that there was no evidence of harmonic structure.

$21.00+$ indicates that the base of the optical event lay behind the limb.

3 In millionths of hemisphere, uncorrected for any foreshortening. 
prominences ejected at the limb. Some were disappearing filaments that ejected matter and were accompanied by the development of two parallel lines of flares, one on either side of the position of the former filament. Others were flares, almost all being particularly bright and showing some evidence of dark-hydrogen activity.

The limb ejections were of high velocity, exceeding the velocity of sound, $170 \mathrm{~km} / \mathrm{second}$, in ionized hydrogen at $10^{\circ} \mathrm{K}$. Two of them (1957 September 24) occurred in an active region, which, during the same day, ejected a number of other surges having velocities of $160 \mathrm{~km} / \mathrm{second}$ or less. This evidence suggests that type II bursts accompany only supersonic ejections.

Heights may be obtained from the optical limb observations by assuming the ejection to lie in a diametric plane. Similarly, burst heights can be obtained by assuming the emission to be at the coronal plasma frequency or in its second harmonic, and by combining the electron density so obtained with the Allen-Baumbach electron-density distribution. In comparing the two sets of heights, it should be noted that there was no clear harmonic structure in any of the type II bursts associated with the limb events. In some cases, evidence from the height-time plots suggested that the emission was in the second harmonic; in others it favored the fundamental.

The theory of a spherically symmetrical corona, however, indicates that the fundamental plasma frequency should not be received from events originating very far from the center of the disk, though the second harmonic should be observable to the limb [1]. On comparing the position of the source with the presence or absence of definite harmonic structure, we find that both harmonics are usually present to about $0.8 R_{\odot}$ from the center of the disk, beyond which there is usually no evidence of harmonic structure. We think that in these latter cases it is the fundamental frequency that is missing.

In any case, the presence of the fundamental well away from the center of the disk indicates that the corona is by no means spherically symmetrical for the purposes of radio frequency propagation. This, and departures from the Allen-Baumbach model, may explain why some of the limb events give unsatisfactory height-time plots for the second harmonic. Perhaps also the optical observations may not have revealed the highest, faintest and fastest parts of the ejection.

\section{REFPRENCE}

[1] Wild, J. P., Murray, J. D., and Rowe, W. C. Aust. J. Phys. 7, 439, 1954. 